\title{
Coparentalidade aos três meses de vida do bebê
}

\author{
Beatriz Schmidt (1) ${ }^{1}$ \\ Vitória Santos Arenhart ${ }^{1}$ \\ Rita de Cassia Sobreira Lopes $\mathbb{1}^{1}$ \\ Cesar Augusto Piccinini (1) 1 \\ ${ }^{1}$ Universidade Federal do Rio Grande do Sul, RS, Brasil
}

\section{Resumo}

O objetivo do presente estudo foi investigar a coparentalidade aos três meses de vida do bebê. Participaram 26 famílias nucleares, com filho único. Mãe e pai responderam a entrevistas. A análise de conteúdo qualitativa revelou responsabilidade predominantemente materna nos cuidados do bebê na maioria das famílias. A mãe parecia ocupar uma posição de guardiã da relação pai-bebê, apresentando comportamentos facilitadores ou inibidores do envolvimento paterno. Todos os participantes mencionaram apoio ao papel coparental, embora também tenha sido identificada depreciação materna à contribuição paterna. O envolvimento triádico ocorria principalmente nos cuidados básicos do bebê. Verbalizações dos genitores sugeriram boa qualidade na comunicação familiar, além de bons níveis de acordo sobre os cuidados. Salientam-se aspectos gratificantes e desafiadores da coparentalidade aos três meses de vida do bebê, período em que os genitores estão se adaptando à nova identidade e aos novos papeis, para atender às necessidades do filho.

Palavras-chave: coparentalidade, relações familiares, desenvolvimento infantil, relações pais-criança.

\section{Coparenting at three months of the baby's life}

\begin{abstract}
The aim of the current study was to investigate coparenting at three months of the baby's life. The participants were 26 nuclear families with an only child. Mother and father participated in interviews. The qualitative content analysis revealed predominantly maternal responsibility in the childcare in most families. The mother seemed to occupy a gatekeeper position in the fatherbaby relationship, showing behaviors which facilitated or inhibited the father's involvement. All the participants mentioned coparental support, although maternal undermining directed to paternal contribution was identified. The triadic interactions occurred specially during basic childcare. Parents' verbalizations suggested good quality in family communication as well as good levels of childrearing agreement. Emphasis is placed on gratifying and challenging aspects of coparenting at three months of the baby's life, the period during which parents are adjusting to their new identities and roles in order to attend to the child's needs.
\end{abstract}

Keywords: coparenting, family relations, childhood development, parent child relations.

\section{La experiencia de la paternidad al final del primer año de vida del bebé}

\section{Resumen}

El objeto fue investigar la coparentalidad a los tres meses de vida del bebé. Participaron 26 familias nucleares, con hijo único. Madre y padre respondieron a entrevistas. El análisis de contenido cualitativo reveló responsabilidad predominantemente materna en los cuidados del bebé en la mayoría de las familias. La madre parecía ocupar una posición de guardiana de la relación padre-bebé, presentando comportamientos facilitadores o inhibidores del envolvimiento paterno. Todos los participantes mencionaron apoyo coparental, no obstante, también haya sido identificada la depreciación materna a la contribución paterna. El envolvimiento tríadico ocurría principalmente en los cuidados del bebé. Verbalizaciones de los genitores sugirieron buena calidad de comunicación familiar, más allá de buenos niveles de acuerdo sobre los cuidados. Se destacan aspectos gratificantes y desafiantes de la coparentalidad a los tres meses de vida, período en que los genitores están adaptándose a la nueva identidad y roles, para atender a las necesidades del hijo.

Palabras clave: coparentalidad, relaciones familiares, desarrollo infantil, relaciones padres-niños. 
Os primeiros meses de vida do bebê podem ser estressantes para os genitores ${ }^{1}$, em particular quando se trata do primeiro filho (Schoppe-Sullivan, Settle, Lee, \& Dush, 2016). Nesse período de transição para a parentalidade, mãe e pai assumem novos papeis, bem como desenvolvem novas identidades, visando ao atendimento das necessidades do bebê (Cowan \& Cowan, 2016). É também nesse momento do ciclo de vida que emerge a relação coparental (Schoppe-Sullivan et al., 2016). Segundo Feinberg (2003), a coparentalidade consiste no modo como os indivíduos coordenam e se apoiam no processo de cuidar e de educar os filhos, caracterizando-se pela responsabilidade compartilhada das figuras parentais no papel de cuidadores. Nessa perspectiva, a coparentalidade é composta por quatro dimensões: divisão de trabalho parental, que envolve a maneira como os cuidados são divididos e a satisfação com essa divisão; apoio versus depreciação coparental, referente à cooperatividade ou hostilidade e competitividade entre os genitores; gerenciamento das interações familiares, concernente ao controle dos genitores sobre a forma como se comunicam, interagem e estabelecem fronteiras nas relações familiares; e, acordo nos cuidados, no que tange a necessidades emocionais, segurança, prioridades educacionais e expectativas sobre o comportamento do filho.

Diferentemente das relações diádicas (i.e., mãefilho ou pai-filho), a coparentalidade abrange a dinâmica relacional da tríade mãe-pai-filho (Böing \& Crepaldi, 2016; Bronte-Tinkew, Scott, Horowitz, \& Lilja, 2009). Como construto psicológico, a coparentalidade esteve inicialmente associada a famílias divorciadas (Frizzo, Kreutz, Schmidt, Piccinini, \& Bosa, 2005), de modo que ainda existem relativamente poucos estudos com genitores coabitantes (Pasinato \& Mosmann, 2016). Não obstante, nos últimos anos, evidenciouse um significativo incremento nas pesquisas sobre a coparentalidade, o que parece se associar à relevância que tal construto assumiu para a compreensão do desenvolvimento individual e familiar (SchoppeSullivan \& Mangelsdorf, 2013). Ademais, os estudos sobre a coparentalidade também ganharam força com o crescente interesse pela paternidade, devido às transformações sociais na direção de uma divisão mais equânime nas tarefas maternas e paternas em relação aos cuidados dos filhos (Maršanić \& Kušmić, 2013), conforme evidenciado por diferentes autores (Balsam, 2008; Piccinini, Silva, Gonçalves, Lopes, \&

\footnotetext{
${ }^{1}$ No presente estudo, o termo genitores será utilizado para designar mãe e pai, conjuntament1,e. $\mathrm{O}$ termo pais será utilizado para se referir apenas aos homens.
}

Tudge, 2012; Polli, Gabriel, Piccinini, \& Lopes, 2016; Zvara, Schoppe-Sullivan, \& Dush, 2013). Ainda assim, a literatura tem sugerido que os cuidados dos filhos permanecem em grande parte sob responsabilidade da mãe, sobretudo nos primeiros meses de vida do bebê (Baxter, Buchler, Perales, \& Western, 2014; Christopher, Umemura, Mann, Jacobvitz, \& Hazen, 2015; McClain \& Brown, 2017; Piccinini et al., 2012).

Por outro lado, destaca-se que a coparentalidade não implica que mãe e pai dividam igualmente tarefas e responsabilidades em relação aos filhos (Feinberg, 2003). Tal acordo poderá ser realizado pelos genitores, com influência do contexto sociocultural (Augustin \& Frizzo, 2015) e das experiências de cada um em suas famílias de origem (Schoppe-Sullivan \& Mangelsdorf, 2013). Logo, a maneira como eles se coordenam nesse processo apresentará variações entre as famílias e, também, ao longo do tempo (Kotila \& Schoppe-Sullivan, 2015; Van Egeren, 2004). Por exemplo, segundo Christopher et al. (2015), durante os primeiros meses de vida do bebê, o principal foco da relação coparental é a oferta dos cuidados necessários para protegê-lo e mantê-lo seguro. Então, a coparentalidade apoiadora nesse período envolve a cooperação entre a mãe e o pai em aspectos relativos aos cuidados do bebê (incluindo suas necessidades físicas e emocionais). Em contrapartida, a depreciação coparental diz respeito à competitividade e à hostilidade dos genitores nesses mesmos aspectos. Com o passar do tempo, o foco da relação coparental se torna mais orientado à socialização do filho, à medida que mãe e pai passam a ensiná-lo formas socialmente competentes de se comportar nas interações com outras pessoas.

Nesse sentido, nos primeiros meses de vida do bebê, as principais dificuldades vivenciadas pelos novos genitores tendem a consistir no compartilhamento dos cuidados e das responsabilidades sobre o filho, para atender às suas necessidades desenvolvimentais (McGoldrick \& Shibusawa, 2016). Quando exacerbadas, tais dificuldades podem gerar importante estresse aos genitores, impactando a relação coparental e o desenvolvimento infantil (McDaniel \& Teti, 2012). Isso costuma ser ainda mais complicado quando mãe e pai têm emprego, em função da sobrecarga feminina, notadamente após o final da licença-maternidade (Pasinato \& Mosmann, 2016), que no Brasil, por exemplo, tem duração de quatro a seis meses (Lei 13.257/2016). Entretanto, situações desafiadoras à relação coparental surgem antes mesmo do término da licença-maternidade, já que a mãe e o pai precisam chegar a um acordo quanto aos cuidados alternativos 
para o bebê², mesmo que ainda tão pequeno, considerando a iminência de retorno da mulher ao mercado de trabalho (Pasinato \& Mosmann, 2015). Nesse processo decisório, insegurança e sentimentos ambivalentes são recorrentemente vivenciados pelos genitores (Piccinini, Polli, Bortolini, Martins, \& Lopes, 2016; Rapoport \& Piccinini, 2004).

Outro aspecto importante da relação coparental nos primeiros meses de vida do bebê é que ela parece predizer a coparentalidade em momentos posteriores (Gadoni-Costa, Frizzo, \& Lopes, 2015), bem como desfechos desenvolvimentais mais adaptativos ao longo de toda a infância (Maršanić \& Kušmić, 2013). Contudo, apesar da importância da coparentalidade nesse período inicial do desenvolvimento infantil, a literatura sobre a temática ainda é relativamente escassa (Bronte-Tinkew et al., 2009; Schoppe-Sullivan et al., 2016; Schoppe-Sullivan \& Mangelsdorf, 2013; Van Egeren, 2004), sobretudo no Brasil (Pasinato \& Mosmann, 2016). Diante do exposto, o objetivo do presente estudo foi investigar a coparentalidade aos três meses de vida do bebê.

\section{Método}

\section{Participantes}

Participaram desse estudo 26 famílias, nucleares e com um único filho, que residiam na região metropolitana de Porto Alegre. O nível de escolaridade dos genitores era variado, tanto no que diz respeito às mães (ensino fundamental: $\mathrm{n}=7$; ensino médio: $\mathrm{n}=6$; ensino superior: $\mathrm{n}=12$; pós-graduação: $\mathrm{n}=1$ ) quanto aos pais (ensino fundamental: $n=8$; ensino médio: $n=6$; ensino superior: $n=11$; pós-graduação: $\mathrm{n}=1$ ). Da mesma forma, também era variado o status ocupacional (Hollingshead, 1975) das mães (baixo status, ex. empregada doméstica: $n=4$; status médio, ex. técnica em enfermagem: $n=10$; alto status, ex. dentista: $n=7$ ) e dos pais (baixo status, ex. zelador: $n=11$; status médio, ex. técnico em eletrônica: $n=4$; alto status, ex. advogado: $n=9$ ). Cinco mães e dois pais não estavam inseridos no mercado de trabalho no momento em que os dados foram coletados. Além disso, das mães inseridas no mercado de trabalho, a maioria estava em licença-maternidade.

A média de idade das mulheres foi de 27 anos ( $\geq 19$ e $\leq 36$ anos) e a média de idade dos homens foi de 29 anos ( $\geq 18$ e $\leq 40$ anos). Na ocasião das entrevistas, os bebês ( $50 \%$ meninas e $50 \%$ meninos) estavam

\footnotetext{
${ }^{2}$ Segundo Rapoport e Piccinini (2004), os cuidados alternativos se referem aos arranjos de cuidados não parentais, em que se destacam o cuidado por parentes da família, babá ou creche.
}

com três meses, em média, e não apresentavam problemas de saúde. Os participantes integraram o Estudo Longitudinal de Porto Alegre: Da Gestação à Escola, 1998-2012 - ELPA, e já haviam participado de uma fase de coleta de dados na gestação, antes de participarem dessa fase coleta de dados aos três meses de vida do bebê. Para fins do presente estudo, foram selecionadas famílias em que a mãe e o pai coabitavam e haviam respondido a todos os instrumentos aplicados nessa fase de coleta de dados, sendo que o bebê era o primeiro filho do casal.

\section{Instrumentos}

Foram utilizados os seguintes instrumentos:

- Ficha de contato inicial, que buscava verificar se a família atendia aos critérios de inclusão na amostra (gestantes primíparas que não apresentavam intercorrências clínicas com elas mesmas ou com o bebê) e coletar dados para posterior contato;

- Entrevista sobre dados demográficos da família, que visava obter informações sobre os participantes, como idade, escolaridade, estado civil, ocupação e religião;

- Entrevista sobre a experiência de maternidade e o desenvolvimento do bebê no primeiro trimestre, que investigava sentimentos maternos, impressões da mãe sobre o pai do bebê, sobre as relações familiares, sobre o crescimento, as habilidades e as características do bebê; e

- Entrevista sobre a experiência de paternidade e o desenvolvimento do bebê no primeiro trimestre, que investigava sentimentos paternos, impressões do pai sobre a mãe do bebê, sobre as relações familiares, sobre o crescimento, as habilidades e as características do bebê.

Algumas das questões da Entrevista sobre a experiência de maternidade e o desenvolvimento do bebê no primeiro trimestre e da Entrevista sobre a experiência de paternidade e o desenvolvimento do bebê no primeiro trimestre que ofereceram evidências sobre a coparentalidade se referiram a: tarefas que cada um dos genitores se engajava regularmente com o bebê e a satisfação quanto a isso; como cada genitor percebia a maneira do outro genitor de se relacionar com o bebê; como a rotina familiar era organizada; dificuldades vivenciadas nos três primeiros meses de vida do bebê. Embora as questões oferecessem um guia, os entrevistadores incentivavam os participantes a falar sobre aspectos que eventualmente não tivessem sido contemplados nas entrevistas, compartilhando suas experiências, o que contribuiu para formar uma perspectiva singular sobre cada família. 


\section{Procedimento}

\section{Coleta de dados}

De acordo com os procedimentos do ELPA, os genitores foram convidados a participar do estudo ainda durante a gravidez. Nesse primeiro momento, a gestante era informada sobre os objetivos do estudo e respondia à Ficha de contato inicial. Se a família atendesse aos critérios gerais de inclusão na amostra, era marcado um encontro na residência dos participantes, quando a mãe e o pai assinavam o Termo de consentimento livre e esclarecido (TCLE) e respondiam à Entrevista sobre dados demográficos da família. Após a coleta de dados na gestação, não utilizada no presente estudo, realizou-se novo contato com as famílias aos três meses de vida do bebê. Nesse momento, os genitores foram convidados a participar de entrevistas e de uma filmagem da interação familiar, na residência da família. No presente estudo, serão analisados apenas os dados da Entrevista sobre a experiência de maternidade e o desenvolvimento do bebê no primeiro trimestre, respondida individualmente pela mãe, e da Entrevista sobre a experiência de paternidade e o desenvolvimento do bebê no primeiro trimestre, respondida individualmente pelo pai. Essas entrevistas eram estruturadas e realizadas de forma semidirigida, com duração aproximada de uma hora; elas foram audiogravadas e transcritas. Os entrevistadores eram estudantes de pós-graduação do curso de Psicologia, que faziam parte da equipe de pesquisa do ELPA.

\section{Análise dos dados}

Os dados foram analisados por meio de análise de conteúdo qualitativa (Laville \& Dionne, 1999), com base nas quatro categorias componentes do conceito de coparentalidade propostas por Feinberg (2003), já definidas anteriormente: divisão de trabalho parental, apoio versus depreciação coparental, gerenciamento das interações familiares e acordo nos cuidados. Duas das autoras do presente estudo, que não realizaram a etapa de entrevistas com os participantes, classificaram todas as respostas de forma independente, ou seja, categorizaram individualmente cada entrevista. Após, dúvidas e discordâncias foram discutidas e resolvidas por consenso.

Embora a aplicação dos instrumentos tenha sido realizada separadamente com cada genitor, na análise dos dados se considerou a dinâmica relacional da tríade mãe-pai-bebê, levando em conta as particularidades de cada família, como sugere a literatura (Maršanić \& Kušmić, 2013). Dessa forma, a unidade de análise para categorização dos relatos foi a família, de modo que as falas poderiam ter sido expressas tanto por um, quanto por ambos os genitores. Isso porque as percepções de apenas um dos genitores já indicam aspectos importantes da dinâmica relacional da tríade mãe-pai-bebê, visto que os membros da família interagem e se influenciam mutuamente. Além disso, face ao número de famílias, para facilitar a exposição dos achados, utilizou-se a seguinte descrição, quanto aos relatos classificados em cada categoria: uma/algumas famílias: 1 a 6 ; muitas famílias: 7 a 13; a maioria das famílias: 14 a 19; a grande maioria/todas as famílias: 20 a 26. Tal classificação foi adaptada com base em Hill et al. (2005).

\section{Considerações éticas}

O ELPA recebeu aprovação do Comitê de Ética da Universidade Federal do Rio Grande do Sul (Resolução $\mathrm{n}$ - 2006596). Todos os participantes assinaram o TCLE. Para preservar o sigilo e a identidade dos participantes, a autoria dos relatos foi identificada pelas letras " $\mathrm{M}$ ", para mãe e, "P", para pai, seguidas do número do caso.

\section{Resultados}

Apresentam-se, a seguir, os resultados separadamente para cada categoria, ilustrando-as com relatos dos participantes ${ }^{3}$.

\section{Divisão de trabalho parental}

Esta categoria compreende relatos de mãe e pai que se referem à distribuição de deveres e responsabilidades sobre a rotina diária de cuidados do bebê, bem como à satisfação quanto a essa divisão. Todas as famílias apresentaram relatos sobre a distribuição das responsabilidades. Contudo, na maioria dos casos, os cuidados do bebê estavam sob responsabilidade predominantemente materna, o que foi evidenciado nas falas das mães: "A maior parte, quem lida com ele sou eu. De noite, quando o [filho] tá ali com a gente, eu acordo, dou mamá, ajeito ele, às vezes troco, e o [pai] nem vê. Tudo com a mãe mesmo" (M9); e dos pais: "Se ela precisa fazer alguma coisa, eu fico com a bebê, né, mas mais do que isso não tem necessidade. Na hora de mamar é com a mãe, na hora de trocar é mãe, banho também" (P24). Em relação a isso, muitas famílias associaram a escassa participação paterna nos cuidados do bebê à intensa atividade laboral: "Fico pouco tempo com ela [filha]. Geralmente eu fico com ela o final de semana, por causa do trabalho, da faculdade" (P12).

Entretanto, muitas famílias apresentaram uma divisão de trabalho mais equilibrada: "Ele é um pai

\footnotetext{
${ }^{3}$ Inúmeros outros exemplos de relatos dos genitores foram categorizados, mas não foram incluídos no presente artigo, por limitações de espaço. Em função disso, aqui também se buscou editar algumas citações, excluindo partes que não eram fundamentais para o seu entendimento ou mesmo acrescentando, entre colchetes, expressões para facilitar a compreensão.
} 
que assim, ó, ele dá banho, ele troca, ele dá mamadeira, faz a mamadeira" (M21); "Eu assumo todas as tarefas. A gente divide igual. Antes eu só não podia dar o seio, que não tinha, hoje eu faço tudo [o bebê, aos três meses, tomava mamadeira]" (P21). Outro resultado interessante é que alguns pais de menina pareciam menos envolvidos nos cuidados básicos da filha, relatando desconforto nessas atividades: "Não troco [fralda]. Banho nunca dei, até vi, fico vendo, não tem problema. O problema é ficar tocando, limpando. Esse tipo de coisa eu não gosto de fazer" (P2); "Gosto de tá junto [na hora do banho], mas não gosto de dar banho, não tenho habilidade. É uma coisa mais entre a mãe e a nenê" (P20).

Com relação à divisão de trabalho, na grande maioria das famílias apareceram relatos acerca da satisfação ou não com esse aspecto. Em muitas famílias, os genitores pareceram satisfeitos quanto a essa divisão: "Eu achava que ele não ia me ajudar tanto quanto ele tá me ajudando. Tô achando ótima a ajuda dele" (M22); "Acho que ela gosta da minha participação. Ela nunca reclamou" (P22). Entretanto, na maioria das famílias, os genitores mostraram insatisfação quanto à divisão de tarefas estabelecida, associada a relatos de sobrecarga materna e de indisponibilidade de tempo por parte do pai: "Eu fico irritada. Ultimamente, eu fico só fazendo essas coisas [cuidados do bebê]. Ele também tem que participar. Eu também gostaria de ficar fazendo outras coisas" (M14); "O tempo que eu tenho com a minha família é muito pouco. Eu gostaria de ter mais [tempo]" (P14).

Além disso, em muitas famílias foi possível notar que a mãe tendia a ocupar a posição de 'guardiã' da interação do pai com o bebê. Nesse sentido, muitas mães pareciam apresentar comportamentos que visavam a estimular o envolvimento paterno: "Ele diz: 'ai, o pai é um desajeitado para isso' [dar banho]. Mas eu digo: "não, aos pouquinhos tu vai aprendendo"" (M9). Porém, em alguns casos, as mães pareciam apresentar comportamentos que acabavam por inibir o envolvimento paterno: "Quando ela tá muito cansada, ela fala que eu não tô ajudando muito, e eu digo: 'pois é, mas se eu tô cuidando dele, tu chega e pega ele"” (P4).

\section{Apoio versus depreciação coparental}

Esta categoria se refere ao quanto cada genitor apoia, valoriza e afirma a competência do outro, ou ainda ao quanto deprecia, hostiliza ou é competitivo com o parceiro. Em todas as famílias apareceram relatos de apoio ao papel coparental. Esse aspecto foi evidenciado tanto por meio das verbalizações maternas: "Ele é supercarinhoso, superpreocupado. A gente vê que ele procura estar, sabe, bem caute- loso" (M23); quanto das verbalizações paternas: "Ela é ótima, supercalma, muito comunicativa com [o filho]. Eu gostaria que [a mãe] pudesse cuidar dele sempre. Mas não dá, ela tem que ter o lado profissional dela. Se realizar por outro lado, né?" (P23).

Em algumas famílias, entretanto, apareceu certo nível de depreciação materna em relação à contribuição paterna: "Ele tava mais atrapalhado. Até o jeito de pegar. [A filha] chorava e ele não conseguia acalmar. Ainda continua, mas melhorou. Não sei se é porque [a mãe] carrega nove meses, mas mãe consegue acalmar mais do que pai" (M5); "Ela começa a chorar e [o pai] vai ficando, vai ficando... [Até que] chega num momento, assim, que ele não aguenta mais. Eu acho que ele poderia, então, treinar mais a tolerância, a paciência" (M13). Ainda sobre a depreciação coparental, não foram identificados relatos paternos que evidenciassem depreciação em relação à contribuição materna.

É interessante destacar que em todos os casos que foram constatados relatos maternos depreciativos, também ocorreram relatos maternos apoiadores, denotando a coexistência de apoio e de depreciação, por parte da mãe em relação ao pai. Esses aspectos são ilustrados por meio das verbalizações a seguir, as quais sugerem ora apoio: "É que ele [pai] trabalha na creche, né? Então, ele já tem assim bastante, acho, experiência, tem o jeito de cuidar (M7); ora depreciação: "Eu achei que ia me preocupar menos porque era o pai, né? Mas, às vezes, ele [filho] se estressa. Tem horas que ele quer uma mulher para dar uma mamadeira" (M7).

\section{Gerenciamento das interações familiares}

Esta categoria diz respeito à forma pela qual os genitores interagem e se comunicam entre si e com outros membros da família, sendo constituída por aspectos referentes ao envolvimento triádico, ao estabelecimento de fronteiras e à comunicação familiar. $\mathrm{Na}$ grande maioria das famílias, os genitores trouxeram relatos sobre envolvimento triádico. Em muitas dessas famílias, os genitores indicaram a hora do banho como o principal momento de interação da tríade mãe-paibebê: "Na hora do banho a gente fica conversando ali, eu e a [mãe], brincando com ele, tirando foto, filmando" (P4). Além disso, em algumas famílias, os genitores referiram o final de semana como o período em que mais ocorria a interação da tríade mãe-paibebê: "No sábado a gente almoça os três juntos e a gente passa o dia só nós três. Dá a ideia mesmo de que, poxa, nós temos mais a nossa vida" (M10). Na maioria das famílias, os genitores também apresentaram relatos quanto a equilíbrio ou desequilíbrio no envolvimento triádico, sendo que na maior parte delas se evidenciou envolvimento triádico equilibrado: "No começou, eu 
me irritava bastante com ela chorando. E o papai que dava um jeito [ajudava]. Até porque daí ele tá de fora da situação. É melhor assim” (M6); “Às vezes ela [mãe] se estressa um pouquinho, eu noto que se irrita, né? Aí eu entro em cena" (P17). Já em algumas famílias, os genitores trouxeram relatos que denotavam certo desequilíbrio no envolvimento triádico: "O [pai] fala pra mim 'vai lá, deixa ele comigo'. Eu não [deixo], tem que estar comigo, sempre. Parece que eu não posso deixar ele" (M22); "Ela [mãe] pensa como fazer. Eu não sei, eu vou por ela" (P11).

Em relação ao estabelecimento de fronteiras, em algumas famílias os genitores apresentaram relatos demonstrando dificuldades para estabelecer fronteiras entre a tríade e a família extensa materna, o que parecia resultar em certa insatisfação paterna. Esse aspecto foi revelado em verbalizações maternas: "O [pai] acha que a [avó materna] se mete muito. Aí ele começou a me xingar: "porque tu deixa, porque tu não fala nada, tu tem que aprender a fazer por ti mesma"' (M19); bem como em verbalizações paternas: "Qualquer dificuldade, ela [mãe] corre pra mãe dela [avó materna]. A educação tem que ser do pai e da mãe" (P10).

A comunicação familiar apareceu no relato dos genitores em algumas famílias. Esses relatos sugeriram uma comunicação de boa qualidade, denotando estratégias construtivas de resolução de conflitos, o que foi referido pelas mães: "A gente procura não gritar, fala bem baixo, com calma" (M18); e pelos pais: "Futuro é uma coisa que a gente não sabe muito bem o que vai acontecer. Planeja. Se não acontecer, a gente vai se comunicar, como a gente tem feito sempre. $\mathrm{O}$ que a gente vai fazer, [vai] decidir em conjunto" (P20).

\section{Acordo nos cuidados}

Esta categoria inclui concordâncias ou discordâncias entre a mãe e o pai acerca de tópicos relacionados ao bebê e envolve cuidados parentais e arranjo de cuidado alternativo. Em algumas famílias, os genitores apresentaram relatos sobre cuidados parentais em que apareceram concordâncias: "A gente estipulou que se ela tá no carrinho e tá bem, não tá chorando, a gente deixa, porque depois se ela pega aquela mania de colo, só querer colo, fica meio complicado" (M6); "A gente se agrada de levar a [filha] para ficar com a família toda, com outras pessoas junto, ajudando, cuidando. Porque não envolve só nós dois, ela tem toda uma família" (P6). Contudo, também apareceram discordâncias: "Quando ele tá chorãozinho, o [pai] acha que é porque ele quer mamar, mas não é mamá, eu acho que não é mamá, porque logo que ele [filho] acorda, ele não é de mamar muito" (M9); "Eu acho que é muito dar manha isso da [mãe] não deixar ela chorar" (P18).
Em relação ao arranjo de cuidado alternativo, em muitas famílias, os genitores trouxeram relatos de concordância quanto à decisão de inserir ou não o bebê na creche, no momento em que a mãe se encontrava na transição entre a licença-maternidade e a volta ao mercado de trabalho. Em algumas dessas famílias, os genitores se referiram à intenção de adiar o ingresso na creche, por meio do compartilhamento dos cuidados do bebê com uma avó: "Vamos deixar ele com a [avó], porque é uma pessoa que a gente confia mais. Depois, quando ficar maiorzinho, a gente vai ver como é que vai ficar. Aí, de repente, tem que colocar na creche" (M9); "A ideia é que a avó cuide. Se não, vamos achar outra pessoa pra cuidar. Se não der, vamos ter que pensar numa creche" (P9); ou com uma babá: "A gente tava muito em dúvida se colocava numa escolinha ou se contratava alguém. Daí descobrimos uma senhora, muito amiga da minha mãe, muito próxima da gente. A gente confia um monte nela. Então, o [filho] vai ficar com ela" (M21); "Optamos por essa pessoa pelos horários flexíveis. Também porque tem muita confiança nessa pessoa. E na creche, ele é mais um, né?" (P21). Já em algumas famílias, os genitores se mostraram decididos a inserir o bebê na creche ao final da licença-maternidade: "A gente tinha pensado em botar uma pessoa em casa pra cuidar dela. [Mas] a gente tem medo, assim, que de repente a pessoa perca a paciência” (M6); “A gente vai botar ela numa creche, aí por março, abril. Já decidimos” (P6).

\section{Discussão}

Analisados em conjunto, os resultados do presente estudo permitem evidenciar semelhanças e particularidades entre as famílias participantes, em relação à coparentalidade aos três meses de vida do bebê. No que diz respeito à divisão de trabalho parental, embora algumas famílias tenham referido compartilhamento equânime, os cuidados do bebê apareceram sob responsabilidade predominantemente materna na grande maioria dos casos. Tais resultados são esperados nesse período do desenvolvimento, pois tradicionalmente a mulher é a principal responsável por atender às necessidades do bebê durante os seus primeiros meses de vida (Baxter et al., 2014; Van Egeren, 2004). Assim, no tocante às narrativas sobre o novo pai, evidencia-se que modelos tradicionais e modernos de paternidade parecem coexistir (Piccinini et al., 2012; Polli et al., 2016). Atualmente, o pai tem vivenciado pressões no sentido de uma maior participação no cuidado dos filhos (Schoppe-Sullivan et al., 2016), mas ele nem sempre se sente apto a essa maior participação, bem como nem sempre tem 
disponibilidade de tempo ou mesmo emocional. Antes do nascimento do bebê, é recorrente que o pai imagine o filho como um companheiro para brincadeiras (Piccinini et al., 2012). Dessa maneira, nos primeiros meses após o nascimento, os homens podem experimentar sentimentos de inadequação e inexperiência, pois o bebê necessita predominantemente de cuidados e não interage de forma tão recíproca quanto o pai eventualmente esperaria.

Além disso, no presente estudo, o emprego do pai foi identificado como um possível entrave à sua maior participação nos cuidados do bebê, como já evidenciado em outras pesquisas (McClain \& Brown, 2017; Pasinato \& Mosmann, 2015; Polli et al., 2016). Conforme McClain e Brown (2017), nas famílias com bebês, comumente a mãe reduz a sua participação no mercado de trabalho e aumenta a quantidade de tempo investido nos cuidados do filho, enquanto o pai tende a aumentar a sua participação no mercado de trabalho, em busca de ampliação do orçamento familiar. Portanto, nesse período há uma tendência de retorno a papeis mais tradicionais de gênero, mesmo quando ambos os genitores têm emprego (Baxter et al., 2014; McClain \& Brown, 2017; McGoldrick \& Shibusawa, 2016). Para Baxter et al. (2014), isso costuma ocorrer porque a transição para a parentalidade se caracteriza como um processo tão marcante no ciclo vital, que se associa a modificações no autoconceito e na identidade da mãe e do pai. Assim, mudanças em concepções anteriormente estabelecidas sobre papeis de gênero são esperadas nesse período, pois os genitores buscam o arranjo de cuidado que consideram o mais adequado para atender às necessidades do bebê em seus primeiros meses de vida.

Vale destacar que na maioria dos casos investigados no presente estudo, as mães estavam em período de licença-maternidade quando as entrevistas foram realizadas, o que proporcionava maior disponibilidade de tempo para a interação da mãe com o bebê. No Brasil, a licença-maternidade é de quatro meses, podendo chegar a seis meses, e a licença-paternidade é de cinco dias, podendo chegar a 20 dias, para servidores públicos e trabalhadores de empresas participantes do Programa Empresa Cidadã (Lei 13.257/2016). Dessa forma, diferentemente de outros países, como os nórdicos (Bungum \& Kvande, 2013), o Brasil não conta com políticas específicas que permitam às famílias optar por ampliar ou distribuir de forma mais equânime o período de licença-maternidade e de licença-paternidade. Assim, a diferença do tempo estabelecido para essas licenças também impacta na divisão de trabalho parental, referendando papeis mais tradicionais de gênero nos cuidados do bebê.
Outro resultado que chamou a atenção foi a aparente diferença de participação do pai nos cuidados básicos, em função do sexo do bebê. Nessa direção, alguns pais de meninas relataram que preferiam não realizar tarefas como troca de fraldas e banho. Esses achados são semelhantes aos do estudo de Balsam (2008), que investigou três pais de meninas, os quais referiam grande desconforto frente à necessidade de realizar cuidados corporais à filha, sobretudo por aspectos ligados a gênero e sexualidade. Por outro lado, Bronte-Tinkew et al. (2009) sugeriram que dentre os motivos para a possível diferença de participação do pai em função do sexo do bebê, pode estar a maior identificação paterna com o filho do mesmo sexo.

No presente estudo, apesar da grande maioria das famílias apresentar divisão de trabalho parental pouco equânime, visto que os cuidados do bebê apareciam sob responsabilidade predominantemente materna, foram identificados tanto relatos de satisfação como de insatisfação quanto a isso. Conforme Feinberg (2003), o principal aspecto a ser considerado na divisão de trabalho parental é a satisfação com a forma de negociar as responsabilidades e com os resultados dessa distribuição. Portanto, avaliar a satisfação com a divisão de trabalho parental permite identificar o quanto as expectativas da mãe e do pai estão sendo atendidas. Quando isso não ocorre, sentimentos de injustiça e mágoa podem emergir, levando ao aumento do estresse parental e à redução da responsividade ao filho e do calor emocional na família. A divisão de trabalho parental é um dos domínios da coparentalidade mais suscetíveis aos períodos do desenvolvimento (Kotila \& Schoppe-Sullivan, 2015). Assim, é possível que para os participantes do presente estudo, transições como o retorno da mãe às atividades laborais, ao final da licença-maternidade, impliquem em renegociação da divisão de trabalho parental e, por conseguinte, em mudanças na satisfação com esse domínio da coparentalidade (Pasinato \& Mosmann, 2016). Nas situações que exigem modificações de regras anteriormente estabelecidas, a flexibilidade parece determinante para o atendimento das necessidades do filho e para o funcionamento familiar (Gadoni-Costa et al., 2015).

No que diz respeito a apoio versus depreciação coparental, genitores de todas as famílias trouxeram relatos sobre coparentalidade apoiadora, o que tem sido consistentemente relacionado à maior qualidade das interações mãe-filho e pai-filho, bem como a trajetórias mais adaptativas de desenvolvimento infantil (Böing \& Crepaldi, 2016; Frizzo et al., 2005; Schoppe-Sullivan et al., 2016). Ademais, para Schoppe-Sullivan et al. (2016), sentir-se apoiado, validado e valorizado 
pelo cônjuge parece ser importante notadamente na transição para a parentalidade. Nesse período de intensas transformações, as novas atividades (que posteriormente tendem a se tornar rotineiras) costumam ser consideradas difíceis pelos genitores, de modo que eles temem o julgamento por outras pessoas, incluindo o cônjuge. Segundo essas autoras, o pai parece particularmente sensível ao apoio da mãe. Nesse sentido, se ele experiencia constrangimento ou se sente ridicularizado ao expressar ideias e opiniões acerca dos cuidados do bebê, a tendência é de pior ajustamento ao papel parental.

A literatura sugere que o apoio e a depreciação coparental podem coexistir em um mesmo sistema familiar (Feinberg, 2003; Schoppe-Sullivan \& Mangelsdorf, 2013), conforme evidenciado no presente estudo. Com relação à depreciação ao papel coparental, foram identificados relatos maternos, mas não paternos. Esse resultado corrobora os achados de Van Egeren (2004), em pesquisa sobre o desenvolvimento da coparentalidade na transição para a parentalidade. Segundo a autora, geralmente as mulheres parecem menos satisfeitas com a coparentalidade em comparação aos homens. Dentre as razões para essa diferença, destaca-se o descontentamento com a divisão de trabalho parental com uma maior sobrecarga materna nos primeiros meses de vida do bebê, face ao seu estado de dependência, como já discutido anteriormente. De acordo com McDaniel e Teti (2012), inclusive aspectos referentes ao sono podem estar associados. O fato de a mãe acordar diversas vezes durante a noite para amamentar ou ninar o bebê, permanecendo em vigília noturna - conforme relatado por algumas participantes do presente estudo -, tende a acarretar desgaste físico e emocional à mulher, o que por sua vez pode prejudicar a relação coparental nesse período, associando-se à maior depreciação da mãe no que diz respeito ao pai. Além disso, problemas de saúde mental, incluindo quadros de depressão, também acabam por afetar a coparentalidade, com maior tendência de dificuldades na expressão de apoio entre os genitores (Feinberg, 2003).

Por outro lado, há famílias em que a mãe assume toda a responsabilidade pelo bebê e, inadvertidamente ou propositalmente, inibe ou exclui o pai de se engajar com o filho (McDaniel \& Teti, 2012; Van Egeren, 2004). Verbalizações nesse sentido foram identificadas no presente estudo, o que pode se relacionar ao sentimento de falta de reciprocidade e à depreciação coparental em alguns casos investigados. Nessa direção, vale salientar relatos sobre situações em que a mãe parece interromper o cuidado do pai ao bebê, para que ela própria passe a fazê-lo, mesmo se dizendo cansada ou sobrecarregada.
Tal como pontuaram Pasinato e Mosmann (2016), ainda quando o pai se mostra participativo na vida do filho, ele pode se sentir excluído, face à concepção de que o cuidado do bebê consiste em uma habilidade natural da mulher. Dessa forma, segundo Zvara et al. (2013), a mãe pode funcionar como guardiã (gatekeeper), no sentido de apresentar comportamentos que dificultam (gateclosing) ou que facilitam (gate-opening) o envolvimento do pai. No presente estudo também foram constatadas verbalizações sobre comportamentos maternos facilitadores, o que é importante, uma vez que a coparentalidade apoiadora parece encorajar o pai a participar mais dos cuidados do filho (Böing \& Crepaldi, 2016; Zvara et al., 2013).

Em relação ao gerenciamento das interações familiares, evidenciou-se que muitas famílias apresentaram relatos referentes à interação da tríade mãepai-bebê, com destaque para o momento do banho. Ainda assim, em função da licença-maternidade e do emprego paterno, essas interações triádicas em sua maioria foram restritas às noites e aos finais de semana. De tal maneira, conforme esperado nesse período do desenvolvimento, parece haver um predomínio de interações da díade mãe-bebê (Piccinini et al., 2012), em comparação às interações da tríade mãe-pai-bebê (Baxter et al., 2014; Van Egeren, 2004). Além disso, evidenciou-se tanto relatos de equilíbrio, quanto de desequilíbrio no envolvimento triádico. Nesse sentido, a função de guardiã muitas vezes assumida pela mãe se mostra presente nas interações da tríade mãe-paibebê. Por exemplo, em brincadeiras entre mãe-paibebê, a mulher costuma liderar ou guiar as interações triádicas, enquanto o comportamento do homem tende a ser centrado nas diretrizes oferecidas pela esposa, que pode implicitamente ou explicitamente encorajá-lo a se engajar na atividade (Van Egeren, 2004).

Sobre o estabelecimento de fronteiras entre a família nuclear e a família ampliada, em alguns casos se evidenciou a insatisfação do pai com o envolvimento de familiares da mãe, em particular da avó materna. Para McGoldrick e Shibusawa (2016), na transição para a parentalidade, como a mãe e o pai não possuem experiência com bebês, é importante que eles aprendam essas habilidades. Assim, em muitas famílias os avós se colocam em segundo plano, de forma a favorecer que seus filhos sejam as autoridades parentais centrais, ao mesmo tempo em que estabelecem outro tipo de relação com os netos, auxiliando no processo de cuidado, quando necessário. Por outro lado, há casos em que esses ajustamentos podem ser estressantes. Por exemplo, Cowan e Cowan (2016) pontuaram que após o nascimento do bebê, tende a ocorrer um aumento de contato entre os novos genitores e as suas famílias 
ampliadas. Contudo, essa maior interação nem sempre é positiva, em particular quando as relações já eram tensas ou ambivalentes antes mesmo da gestação. Assim, novos genitores podem se sentir julgados e avaliados, sem saber como responder a críticas vindas de avós. Não obstante, é importante notar que apenas algumas famílias no presente estudo apresentaram relatos no que tange ao estabelecimento de fronteiras com a família ampliada. Entende-se que isso pode estar ocorrendo em função da redução cada vez maior do convívio geograficamente próximo com as famílias ampliadas, especialmente pela migração de pessoas das cidades menores às cidades maiores (Rapoport \& Piccinini, 2004).

Ainda sobre o gerenciamento das interações familiares, alguns participantes do presente estudo referiram comunicação de boa qualidade com o cônjuge, com destaque às estratégias construtivas de resolução de conflitos referentes à coparentalidade. Segundo Augustin e Frizzo (2015), a comunicação de boa qualidade entre a mãe e o pai pode facilitar a realização de acordos, tanto quanto a resolução de conflitos. Dessa maneira, constitui-se em um importante recurso das famílias para adaptação a novos papeis e demandas relativas à transição para a parentalidade (Pasinato \& Mosmann, 2016). Similarmente, BronteTinkew et al. (2009) sugeriram que melhores níveis de comunicação estão ligados à coparentalidade mais apoiadora, consistindo em fator de proteção ao desenvolvimento individual e familiar.

No que corresponde ao acordo quanto aos cuidados, nas entrevistas do presente estudo se destacaram verbalizações referentes aos cuidados parentais e aos cuidados alternativos. Sobre os cuidados parentais, foram referidos aspectos da forma de cuidar, das necessidades do bebê e da rotina na família, com relatos tanto de concordância quanto de discordância entre a mãe e o pai. Tais resultados são esperados nesse período, pois os genitores estão se adaptando às mudanças desencadeadas com a transição para a parentalidade, incluindo o modo de se relacionar com o cônjuge e com o bebê (Cowan \& Cowan, 2016). Assim, conflitos sobre os cuidados parentais costumam emergir nos primeiros meses do bebê, o que pode trazer estresse aos genitores (McGoldrick \& Shibusawa, 2016). Conforme discutido anteriormente, nos casos em que a comunicação é favorável, a resolução desses conflitos e a realização de acordos tende a ser facilitada (Augustin \& Frizzo, 2015; Pasinato \& Mosmann, 2016).

Sobre o acordo quanto aos cuidados alternativos do bebê após o término da licença-maternidade, três arranjos foram destacados pelos participantes do presente estudo: o cuidado por avó, o cuidado por babá e o cuidado pela creche. Decidir o arranjo de cuidado do filho, ao longo dos seus primeiros meses de vida, costuma ser desafiador para os genitores (Rapoport \& Piccinini, 2004). Esse processo de decisão é vivenciado pela maioria das famílias, em diferentes culturas, e pode suscitar a emergência de diversos sentimentos, entre eles o de culpa, pela seleção de um arranjo em detrimento de outro. Em geral, conforme Piccinini et al. (2016), os genitores que optam por manter o filho no conforto e na segurança do lar, ao invés de colocálo na creche, pautam-se na crença de que os bebês necessitam de um atendimento mais individualizado, como evidenciado por meio dos relatos dos participantes do presente estudo. Nessa direção, temse ainda o estigma relacionado à creche, associando-a a uma instituição nem sempre muito confiável para os cuidados do bebê (Rapoport \& Piccinini, 2004). Assim, quando têm o auxílio de outros familiares, ou mesmo reúnem recursos financeiros para a contratação de babá, os genitores podem optar por não colocar o filho na creche (Piccinini et al., 2016), como ocorreu com algumas famílias investigadas.

\section{Considerações finais}

O presente estudo investigou a coparentalidade aos três meses de vida do bebê e revelou a coexistência de diferenças e de semelhanças nas dinâmicas de relação coparental. Por exemplo, embora a mãe comumente fosse a principal responsável pelos cuidados do bebê, a divisão de trabalho parental se revelou satisfatória para muitas famílias, ao passo que insatisfatória para a maioria. Por outro lado, enquanto em muitas famílias a mãe tendia a encorajar o pai a participar dos cuidados do bebê, em alguns casos esse maior envolvimento paterno parecia ser desestimulado. Não obstante, em todas as famílias se evidenciou apoio coparental, o que consiste em fator protetor do desenvolvimento familiar e infantil. Cabe salientar que nem sempre os genitores fizeram referências às categorias analisadas. Assim, é possível que essas categorias não deem conta de toda a complexidade envolvida na coparentalidade durante a transição para a parentalidade, fase em que alguns sentimentos ainda estão sendo vivenciados e nem sempre são manifestados em uma entrevista.

De tal forma, o presente estudo destaca a importância de se examinar as particularidades de cada dinâmica coparental, considerando sentimentos, expectativas e comportamentos da mãe e do pai aos três meses de vida do bebê, período em que os genitores, especialmente os primíparos, estão se adaptando à 
nova identidade, bem como assumindo novos papeis, face à necessidade de atender às demandas do filho. A emergência da relação coparental, nos primeiros meses de vida do bebê, consiste em um processo normativo do ciclo de vida, que pode fortalecer os vínculos familiares, ao mesmo tempo em que também pode ser vivenciado de modo estressante. Assim, ressaltase a importância de se pensar em intervenções que visem a oferecer escuta sensível e suporte à tríade mãe-pai-bebê nesse momento, o que contribuirá para o desenvolvimento das relações familiares e, em especial, do bebê. Outrossim, sugere-se que estudos futuros investiguem a coparentalidade em outras etapas do ciclo de vida (por exemplo, quando do nascimento do segundo filho ou na adolescência) e também junto a famílias com configurações diversas (por exemplo, famílias homoparentais ou divorciadas), o que trará importantes contribuições para a área.

\section{Referências}

Augustin, D. \& Frizzo, G. B. (2015). A coparentalidade ao longo do desenvolvimento dos filhos: Estabilidade e mudança no $1^{\mathrm{O}}$ e $6^{\mathrm{O}}$ ano de vida. Interação em Psicologia, 19(1), 13-24. doi:10.5380/psi.v19i1.29239

Balsam, R. H. (2008). Fathers and the bodily care of their infant daughters. Psychoanalytic Inquiry, 28(1), 60-75. doi:10.1080/07351690701787119

Baxter, J., Buchler, S., Perales, F., \& Western, M. (2014). A life-changing event: First births and men's and women's attitudes to mothering and gender divisions of labor. Social Forces, 93(3), 989-1014. doi:10.1093/sf/sou103

Böing, E. \& Crepaldi, M. A. (2016). Relação pais e filhos: Compreendendo o interjogo das relações parentais e coparentais. Educar em Revista, 59(1), 17-33. doi:10.1590/0104-4060.44615

Bronte-Tinkew, J., Scott, M. E., Horowitz, A., \& Lilja, E. (2009). Pregnancy intentions during the transition to parenthood and links to coparenting for first-time fathers of infants. Parenting: Science and Practice, 9(1-2), 1-35. doi:10.1080/15295190802656729

Bungum, B. \& Kvande, E. (2013). The rise and fall of cash for care in Norway: Changes in the use of child-care policies. Nordic Journal of Social Research, 4(1), 31-54 doi:10.15845/njsr.v4i0.241

Christopher, C., Umemura, T., Mann, T., Jacobvitz, D., \& Hazen, N. (2015). Marital quality over the transition to parenthood as a predictor of coparenting. Journal of Child and Family Studies, 24(12), 3636-3651. doi:10.1007/ s10826-015-0172-0

Cowan, P. A. \& Cowan, C. P. (2016). Transições familiares normativas, qualidade da relação do casal e desenvolvimento sadio dos filhos. In F. Walsh (Org.), Processos normativos da família (pp. 428-451). Porto Alegre, RS: Artmed. (DOI INEXISTENTE)

Feinberg, M. E. (2003). The internal structure and ecological context of coparenting: A framework for research and intervention. Parenting: Science and Practice, 3(2), 95-131. doi:10.1207/S15327922PAR0302_01

Frizzo, G. B., Kreutz, C. M., Schmidt, C., Piccinini, C. A., \& Bosa, C. (2005). O conceito de coparentalidade e suas implicações para a pesquisa e para a clínica. Revista Brasileira de Crescimento e Desenvolvimento Humano, 15(3), 84-93. Recuperado de http://pepsic.bvsalud.org/pdf/rbcdh/v15n3/10.pdf.

Gadoni-Costa, L. M., Frizzo, G. B., \& Lopes, R. C. S. (2015). A guarda compartilhada na prática: Estudo de casos múltiplos. Temas em Psicologia, 23(4), 901-912. doi:10.9788/TP2015.4-08

Hill, C. E., Knox, S., Thompson, B. J., Williamns, E. N., Hess, S. A., \& Ladany, N. (2005). Consensual qualitative research: An update. Journal of Counseling Psychology, 52(2), 1-30. doi:10.1037/0022-0167.52.2.196

Hollingshead, A. B. (1975). Four-factor index of social status. (Unpublished manuscript) Department of Sociology, Yale University, New Haven. (DOI INEXISTENTE)

Kotila, L. E. \& Schoppe-Sullivan, S. J. (2015). Integrating sociological and psychological perspectives on coparenting. Sociology Compass, 9(8), 731-744. doi:10.1111/soc4.12285

Laville, C. \& Dionne, J. (1999). A construção do saber: Manual de metodologia da pesquisa em ciências humanas. Porto Alegre, RS: Artmed. (DOI INEXISTENTE)

Lei no 13.257 , de 8 de março de 2016. Estabelece princípios e diretrizes para a formulação e a implementação de políticas públicas para a primeira infância. (2016). Diário Oficial da União: seção 1, 46, 1-4.

Maršanić, V. B. \& Kušmić, E. (2013). Coparenting within the family system: Review of literature. Collegium Antropologicum, 37(4), 1379-1384. Retrieved from https://www.ncbi.nlm.nih.gov/pubmed/24611362.

McClain, L. \& Brown, S. L. (2017). The roles of fathers' involvement and coparenting in relationship quality among cohabiting and married parents. Sex Roles, 76(5-6), 334-345. doi:10.1007/s11199-016-0612-3

McDaniel, B. T. \& Teti, D. M. (2012). Coparenting quality during the first three months after birth: The role of infant sleep quality. Journal of Family Psychology, 26(6), 886-895. doi:10.1037/a0030707

McGoldrick, M. \& Shibusawa, T. (2016). O ciclo vital familiar. In F. Walsh (Org.), Processos normativos da família (pp. 375-398). Porto Alegre, RS: Artmed. (DOI INEXISTENTE) 
Pasinato, L. \& Mosmann, C. P. (2015). Coparentalidade em genitores de bebês com indicativos de dificuldades de inserção escolar. Psicologia Escolar e Educacional, 19(1), 31-40. doi:10.1590/2175-3539/2015/0191791

Pasinato, L. \& Mosmann, C. P. (2016). Transição para a parentalidade e a coparentalidade: Casais que os filhos ingressaram na escola ao término da licença-maternidade. Avances en Psicología Latino-Americana, 34(1), 129-142. doi:10.12804/ap134.1.2016.09

Piccinini, C. A., Polli, R. G., Bortolini, M., Martins, G. D., \& Lopes, R. C. S. (2016). Razões maternas para colocar ou não o bebê na creche no primeiro ano de vida da criança. Arquivos Brasileiros de Psicologia, 68(3), 59-74. Retrieved from http://pepsic.bvsalud.org/pdf/arbp/v68n3/06.pdf.

Piccinini, C. A., Silva, M. R., Gonçalves, T. R., Lopes, R. C. S., \& Tudge, J. (2012). Envolvimento paterno aos três meses de vida do bebê. Psicologia: Teoria e Pesquisa, 28(3), 303-314. doi:10.1590/S0102-37722012000300006

Polli, R. G., Gabriel, M. R., Piccinini, C. A., \& Lopes, R. C. S. (2016). Envolvimento paterno aos 12 meses de vida do bebê. Psico, 47(3), 198-208. doi:10.15448/1980-8623.2016.3.23205

Rapoport, A. \& Piccinini, C. A. (2004). A escolha do cuidado alternativo para o bebê e a criança pequena. Estudos de Psicologia, 9(3), 497-503. doi:10.1590/S1413-294X2004000300012

Schoppe-Sullivan, S. J., \& Mangelsdorf, S. C. (2013). Parent characteristics and early coparenting behavior at the transition to parenthood. Social Development, 22(2), 363-383. doi:10.1111/sode.12014

Schoppe-Sullivan, S. J., Settle, T., Lee, J. K., \& Dush, C. M. K. (2016). Supportive coparenting relationships as a haven of psychological safety at the transition to parenthood. Research in Human Development, 13(1), 32-48. doi:10.1080 15427609.2016.1141281

Van Egeren, L. A. (2004). The development of the coparenting relationship over the transition to parenthood. Infant Mental Health Journal, 25(5), 453-477. doi:10.1002/imhj.20019

Zvara, B. J., Schoppe-Sullivan, S. J., \& Dush, C. K. (2013). Fathers' involvement in child health care: Associations with prenatal involvement, parents' beliefs, and maternal gatekeeping. Family Relations, 62(4), 649-661. doi:10.1111/ fare. 12023

Dados dos autores:

Beatriz Schmidt - Pós-Doutoranda, Universidade Federal do Rio Grande do Sul.

Vitória Santos Arenhart - Psicóloga, Universidade Federal do Rio Grande do Sul.

Rita de Cassia Sobreira Lopes - Doutora, Universidade Federal do Rio Grande do Sul.

Cesar Augusto Piccinini - Doutor, Universidade Federal do Rio Grande do Sul.

Endereço para correspondência:

Beatriz Schmidt

Rua Ferreira Viana, 187, apto 801

90670-100, Porto Alegre, RS, Brasil

E-mail: psi.beatriz@gmail.com

Recebido em: 24/07/2017.

Aceito em: 21/06/2018.

Publicado em: 09/05/2019. 